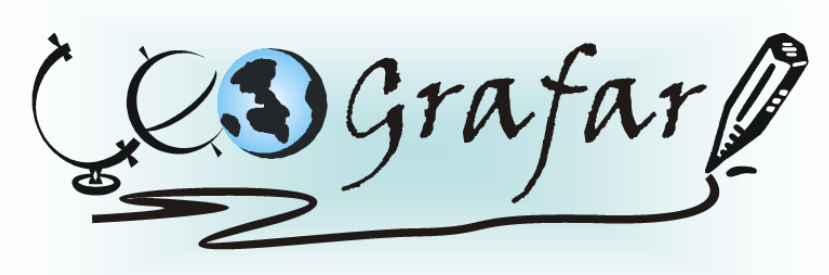

Revista Eletrônica do Programa de Pós-Graduação em Geografia - UFPR

\title{
CULTURA DE ARROZ POR VIA DE CICLO NATURAL DE ENCHENTES: UMA ANÁLISE AMBIENTAL
}

\author{
REGNALDO GOUVEIA DOS SANTOS ${ }^{1}$
}

\begin{abstract}
Resumo: Por perceber grande preocupação com a relação presente e futura entre sociedade e natureza, aqui é apontado um modelo de se cultivar arroz de forma a não degradar o meio ambiente, contribuindo, pois, com o desenvolvimento sustentável. Seguindo essa linha de pensamento, o presente estudo mostra as vantagens do sistema de cultivo em questão. Diante de tais preocupações, dois assuntos foram destacados: o primeiro levanta a questão do inadequado uso de irrigação em cultura de arroz e o segundo enfatiza a importância do referido modelo cultural avaliando a principal várzea do município, Porto da Folha/SE, como uma Área de Preservação Permanente (APP), por exemplo.
\end{abstract}

Palavras-chave: Meio Ambiente; Cultivo de Arroz por Povo Ribeirinho; Irrigação.

\section{CULTURE OF RICE BY THE NATURAL CYCLE OF FLOODS: AN ENVIRONMENTAL ANALYSIS}

Abstract: By realizing the great concern with present and future relationship between society and nature, this work presents a model to grow rice in order not to degrade the environment, what contributes to the sustainable development. Following this line of thinking, this study shows the benefits of cropping systems reported. Due to such concerns, two questions outcome: the first one is concerned with the inappropriate use of irrigation in rice cultivation and the second one emphasizes the importance of the cultural model assessing the main meadow of the municipality, Porto da Folha/SE as an Area Permanent Preservation (APP), for example.

Keywords: Environment; Cultivation of Rice in River People; Irrigation.

\footnotetext{
1 Mestrado em Geografia Humana, Faculdade de Filosofia, Letras e Ciências Humanas Universidade de São Paulo. Professor PEB II - Geografia - Secretaria de Estado da Educação do Estado de São Paulo. E-mail: regnaldogouveia@usp.br, regnaldogouveia@bol.com.br.
} 


\section{INTRODUÇÃO}

A partir de meados do século $X X$, o homem volta suas atenções mais precisamente para as questões ambientais. Preocupado com o futuro da sociedade e do modo de desenvolvimento da economia perante o capital globalizado, busca encontrar uma saída corretamente viável tanto para o meio socioeconômico quanto para o meio natural, ou seja, uma economia sustentável. Para a confirmação desta maneira de se desenvolver é preciso viabilizar a relação homem natureza. Nessa concepção, os próprios atores (governos e a sociedade em geral), em conjunto, devem se unir a um objetivo comum, de modo que se desenvolvam sem conflitos. Com isso, é esperado que danos intensos sejam evitados contra o habitat natural, este que é tão necessário à vida humana, haja vista que o contrário pode acarretar prejuízos incalculáveis para as gerações futuras.

Dessa concepção partem quatro objetivos que o presente estudo alcançou, de forma que foi possível: contextualizar o modelo de se cultivar arroz procurando a forma mais viável a não gerar impactos negativos sobre o meio ambiente; aventar vantagens de desenvolver cultura de arroz por via de ciclo natural de enchentes preservando o meio ambiente; analisar o mal uso de irrigação em cultura de arroz; discutir o modelo em epígrafe avaliando a várzea como Área de Preservação Permanente.

Tais objetivos foram propostos no projeto por serem relevantes ao contexto das variáveis produção e transformação do espaço geográfico da região do Baixo São Francisco Sergipano (BSFS) devido à ação antrópica. Assim, espera-se estar contribuindo com a sociedade em geral, em termos de compreensão dessas variáveis, e com a ciência no sentido da forma com que as referidas variáveis aqui são abordadas. 


\section{MÉTODO}

A metodologia do trabalho apresenta dois momentos: no primeiro foi feito o levantamento bibliográfico de temas pertinentes a presente pesquisa; no segundo, desde 1954 até a década de 1990, foram levantados dados junto ao Instituto de Geografia e Estatística (IBGE) sobre a cultura de arroz desenvolvida pela população ribeirinha do Baixo São Francisco, especialmente em Porto da Folha/SE. Neste caso, foram enfatizados os anos de 1974 até 1990. Tais dados foram tabulados, de forma que resultaram em informações relevantes ao contexto do trabalho.

\section{O modelo de se cultivar arroz procurando a forma mais viável a não gerar impacto negativo sobre o meio ambiente}

O modelo de se cultivar arroz por via de ciclo natural de enchentes foi o único e exclusivamente que se adequou ao clima do município de Porto da Folha/SE e a seus aspectos naturais, de forma que não degradava o meio ambiente. Isso foi notório até enquanto ali não sofria políticas territoriais inadequadas. Quanto aos aspectos naturais do lugar prevalece o clima semiárido, atualmente com vegetação muito escassa e seca. Além disso, é possível observar a paisagem cinzenta com vegetação xerófila originária do Nordeste e temperaturas muito elevadas, ao contrário do baixo índice pluviométrico, em razão de vários anos sem chover no lugar.

A maneira que a comunidade ribeirinha do BSFS cultivava o arroz nas várzeas do rio São Francisco até meados do século $X X$, principalmente os ribeirinhos de Porto da Folha/SE, corrobora o tema deste estudo.

Segundo Santos (2008), antes de as áreas de várzeas do referido município serem inundadas entre novembro e março de cada ano, os meeiros, arrendatários e pequenos proprietários preparavam as terras para o cultivo do arroz apoiando-se em técnicas rudimentares como o uso de enxadas, chibancas, etc. O plantio começava em abril e a colheita terminava por volta de setembro. À medida que o nível do rio aumentava, a comunidade local procurava proteger-se. Com o retorno das águas ao São Francisco, após a inundação das pequenas lagoas modeladas dentro das 
grandes várzeas, cada um dos lavradores começava o cultivo desde a semeadura, passando pelo transplante, o corte do arroz ainda em palha, até a batedura do cereal. Tudo isso era feito à força braçal, nenhuma tecnologia ali estava presente, tampouco a utilização de insumos ou agrotóxicos.

Os lavradores, ao invés de usarem fertilizantes químicos para o aumento da produção, apenas valiam-se da seleção de sementes, o que sempre deu certo.

Ao contrário das grandes monoculturas em que única espécie de cultura se apresenta, no modelo em epígrafe o cultivo de diversas culturas (no caso de Porto da Folha/SE, o arroz no alagado e o feijão, milho, melão, abóbora, melancia, etc., nos combros, terras enxutas) é frequente, propiciando suas autodefesas contra pragas que poderiam aparecer sobre os legumes. Chamou a atenção, neste caso, a presença de pássaros que sobrevoavam as lavouras devido à bela paisagem e densa vegetação que existiam margeando as várzeas, pois que os mesmos eram os principais combatentes dos insetos que ameaçavam a cultura de vazante no BSFS, principalmente no lugar estudado.

Após a proteção das lavouras ser confirmada, em relação a problemas de pragas, os pássaros eram combatidos (vigiados), impedidos de interromperem a produção, através de instalações de bonecos de pano ou de vestes humanas, em meio às lavouras. Até a presença dos lavradores que muitas vezes se instalavam nas várzeas e só se ausentavam depois da etapa da colheita contribuía com o episódio. Cabe ressaltar aqui que os pássaros não eram mortos, mas apenas espantados para não eliminarem as sementes, pois os mesmos retornavam após a colheita e bem se alimentavam com os restos de sementes que se perdiam nos lotes (subdivisões das várzeas para o cultivo do arroz).

O modelo de cultura de arroz em epígrafe deu certo em Porto da Folha/SE até enquanto ali não sofria políticas territoriais inadequadas. Políticas estas que poderiam ter sido implantadas com bons olhos e com o bem de, pelo menos, desenvolver aquele lugar sustentavelmente. Com isso, facilitar o consumo de produtos oferecidos pelas regiões mais bem desenvolvidas, a exemplo das "políticas territoriais implantadas na União Européia" conforme Neli Mello (2006, informação 
verbal) $)^{2}$. Nessa concepção, ali poderia ter recebido investimentos diretos por meio de desenvolvimento de projetos eficientes que envolvessem uma eficaz viabilidade entre o desenvolvimento socioeconômico local e seu meio ambiente, ao invés da ausência de fiscalização ambiental quanto à implementação do projeto hidroelétrico de Xingó. Além da ausência de implantações de projetos de reparação de danos, causa de abandono da principal várzea do lugar, foram observadas faltas de ações de governo como a mitigação dos impactos socioambientais, apesar de ser necessária ao município. Isso foi observado no período da decadência da cultura arrozeira que se desenvolvia com o auxílio do ciclo natural das enchentes. Tal ciclo era o principal fator da existência da cultura substancial de grande parte da sociedade local.

Tais assertivas ratificam que, Porto da Folha/SE, por se localizar à montante de Propriá/SE, sofreu políticas território regionais inadequadas tendo em vista os impactos socioambientais que se alastraram no lugar de acordo com Santos (2008). Apesar disso, sua várzea principal estava inclusa às outras levantadas em projetos emergenciais, mas não foi beneficiada com tais projetos de maneira efetiva. Referentemente a isso, segundo Vargas (1999, p. 106-107):

\begin{abstract}
Mesmo propondo a indenização de todas as várzeas levantadas, o texto é claro [...], todas as demais situadas à montante de Própria não seriam afetadas pela subida do nível da água nos períodos de estiagem "grifo do autor" e, em seguida, explicita que a escolha das soluções para cada várzea foi objeto de discussão com a CODEVASF e entre esta e o Banco Mundial [...].

Em síntese, o Projeto Emergência resultou em duas linhas de ação. A construção de $110 \mathrm{~km}$ de diques e 10 estações de bombeamento à jusante de Propriá constituiu o segmento de obras e, [...], concentrou seus esforços na desapropriação das terras, na construção de sistemas de irrigação e na redistribuição de terras para o pessoal atingido, isto é, para meeiros e arrendatários.
\end{abstract}

Com tudo isso, foi possível observar que até os dias de hoje, vários dos municípios beneficiados com projetos dirigidos pela Companhia de Desenvolvimento dos Vales do São Francisco e do Parnaíba (CODEVASF) continuam produzindo o arroz nas várzeas, ao passo que conforme o que foi citado, no município de Porto da

\footnotetext{
${ }^{2}$ Aula ministrada por Neli Mello, Faculdade de Filosofia, Letras e Ciências Humanas, da Universidade de São Paulo, em 25 de abril de 2006.
} 
Folha/SE a produção arrozeira foi extinta. Quanto a esse episódio, partem duas premissas: a primeira é a consequência da existência da barragem de Xingó. A segunda, de acordo com Vargas (1999), demonstra que as políticas de reparação de danos ali implantadas não foram eficazes diante da extrema necessidade de políticas permanentes e eficientes que o caso requeria, pois da cultura que era desenvolvida na várzea, grande parcela da sociedade local sobrevivia, senão toda população.

Depois do ciclo do arroz, nenhum tipo de dique foi constatado na área da várzea de Porto da Folha/SE. Apenas um sistema de irrigação obsoleto se faz presente a poucos ribeirinhos que cultivam tão somente em estreita faixa da beira do rio São Francisco distante do leito, cerca de $5 \mathrm{~m}$ a $100 \mathrm{~m}$, mas não na várzea. Assim, observa-se que as políticas territoriais que se fizeram presentes naquele município não foram justas ante sua capacidade de produção em meados do século $X X$, visto que conforme Sergipe (1972 apud Vargas, 1999) de 1967 a 1969, essa capacidade foi de $1927 \mathrm{~kg} / \mathrm{ha}$. Em contrapartida, atualmente, o referido município sequer produz $1 \mathrm{~kg}$ de arroz devido ao funcionamento da barragem Xingó.

Referentemente a isso, de acordo com Vargas (1999, p. 75):

As inúmeras pequenas e médias várzeas mantiveram o sistema tradicional de plantio até 1994, quando as obras de controle da vazão do rio foram completadas com a construção da barragem de Xingó, o que acarretou, pela diminuição do volume, o abandono das várzeas para o plantio.

Enfim, antes de tudo é relevante frisar que o cultivo do arroz nas várzeas do Baixo São Francisco Sergipano, na maneira que era realizado se caracterizava como viável ao sonhado modelo de desenvolvimento sustentável, muito discutido no mundo contemporâneo. No entanto, foi possível observar que esse modelo não pôde prevalecer diante do sistema de economia capitalista que neste início de século tem deixado evidenciar alguns de seus pontos fracos como a atual crise financeira que atinge todo 0 mundo. Contudo, se a ação humana não fosse, plena e exclusivamente, voltada para o sistema de economia contemporâneo, ou seja, pensasse num desenvolvimento equânime entre a sociedade, economia e o meio ambiente, a cultura arrozeira de todo o vale do BSFS poderia continuar existindo. 
Para tanto, nem haveria a necessidade do uso de tecnologia, nem a exclusão de classes quanto à atividade cultural dos ribeirinhos do vale do São Francisco que se localizam no Baixo curso do rio. Assim, estima-se que as injustiças sociais que alguns chegaram a reclamar sobre a relação proprietário e meeiro poderiam chegar ao fim através de fiscalização do Ministério do Trabalho, a quem compete tal ação de Estado.

\section{Vantagens de desenvolver cultura de arroz por via de ciclo natural de enchentes, preservando o meio ambiente}

Desenvolver a cultura do arroz em várzeas inundáveis, cíclica e naturalmente, principalmente em lugares que a natureza age a seu favor, representa o meio mais viável quanto ao aspecto ecológico. Em razão disso, é necessário que haja um planejamento adequado no tocante ao aspecto natural, de forma que não venha afetar nem o desenvolvimento da geração presente e futura, nem o espaço natural que está sendo utilizado.

São várias as vantagens apresentadas por esse modelo. Merece destaque, nesse sentido, o preenchimento das lagoas através das enchentes sem necessidade da força humana em tal ação. Além disso, essas lagoas eram normalmente modeladas pela própria natureza por meio da força das águas e o depósito dos sedimentos aluviais (fertilizantes naturais). Neste caso, o arroz era plantado no alagado e, antes de tudo, as lagoas eram preparadas para o cultivo da lavoura, não existiam herbicidas para combater as pragas. Ao invés do uso de agrotóxicos, havia, naquelas intermediações, revoadas de pássaros que protegiam as lavouras das pragas. Bonecos de pano eram instalados em meio às lagoas para que no intervalo, desde a entressafra até o fim da colheita, a produção não fosse ameaçada por tais pássaros. Estes que, ao final da colheita, se alimentavam com as sementes que se perdiam espalhadas sobre o solo. Todo o período de entressafra colaborava com a presença daqueles, pois de uma forma ou de outra, pouco ou muito, se alimentavam da lavoura e de outras sementes vegetais naturais da caatinga, preservando, assim, a manutenção e identidades natural regionais.

Além disso, não ocorria o desmatamento daquela área de maneira devastadora 
porque a própria ação da natureza colaborava com o lugar, de forma que não era necessário desmatar a várzea para plantar o arroz juntamente com os outros diversos legumes. Isso se justifica também porque as referidas inundações impediam o crescimento de vegetações rasteiras naquele lugar e, no momento de estiagem, quando aquela área se encontrava plenamente seca, a grande intensidade do sol colaborava com a interrupção do avanço desse tipo de vegetação.

Entretanto, com a cultura do arroz em plena várzea, foi observada a ausência da vegetação de grande porte (floresta tropical hidrófila de várzea) em seu interior, exceto em suas margens que sempre se apresentaram com exuberante paisagem e equilíbrio ecossistêmico. Este que estava caracterizado, segundo Santos (2008), entre outras maneiras, pela fauna e flora existentes antes da extinção do ciclo de cheias naturais.

Entre as diversas vantagens desse paradigma, apresenta-se também a autofertilização natural do solo das várzeas que ocorria frequentemente através das enchentes cíclicas naturais. Isso chama a atenção para a questão de impacto ambiental, o que está ausente a este modelo de desenvolvimento que se caracteriza ao “[...] 'eco-desenvolvimento' (Sachs, 1980; 1986; Sachs et.al, 1981), 'um outro desenvolvimento' (Fondation Dag Hammarskjold, 1975), 'desenvolvimento local endógeno' (CIRED, 1986), 'desenvolvimento sustentável' (WCED, 1987 e Pearce et.al, 1990) ou 'desenvolvimento durável' (Passet, 1992)”, (apud Paulo Freire Vieira; Jacques Weber, 2002, p. 19), como quiser chamar.

É relevante chamar a atenção do Poder Público para este modelo de desenvolvimento de cultura natural que quase não sofre influência humana em relação à alteração do meio, bem como os importantes resultados que foram obtidos no período que se antecedeu à criação das várias barragens em todo o curso do milagreiro rio brasileiro, São Francisco. Chamar a atenção para que os erros não persistam ocorrendo por meio de impactos ambientais através da ação antrópica, muitas vezes para satisfazer a interesses do sistema capitalista. Sistema este que atualmente já se pode enxergar como um problema social, pois muitas de suas características são principais causas da desigualdade social atualmente percebida.

Este modelo de desenvolvimento de cultura não só é viável ao aspecto natural, mas também ao desenvolvimento da sociedade local e regional conforme as 
necessidades atuais. Estas que buscam atrelar o desenvolvimento econômico à preservação ambiental.

A certeza dessa viabilidade econômica ficou cravada no sucesso da cultura arrozeira de Porto da Folha/SE com seu modelo de desenvolvimento, de forma que o mesmo não acontecia através de máquinas com tecnologias avançadas ou com aplicação de insumos na atividade agrícola, mas através das técnicas do Sertanejo segundo Cunha (1997). Essas que dependiam diretamente do uso da força braçal dos ribeirinhos.

O mapa ratifica que foi considerável o resultado da cultura arrozeira naquele município e em todo o Baixo São Francisco Sergipano, conforme pesquisa realizada acerca do histórico de produção agrícola municipal junto ao Instituto Brasileiro de Geografia e Estatística (IBGE) (1954; 1974-1990).

FIGURA 01. FONTE: IMPACTOS SOCIOAMBIENTAIS À MARGEM DO RIO SÃO FRANCISCO: UM ESTUDO DE CASO (2008, P. 116).

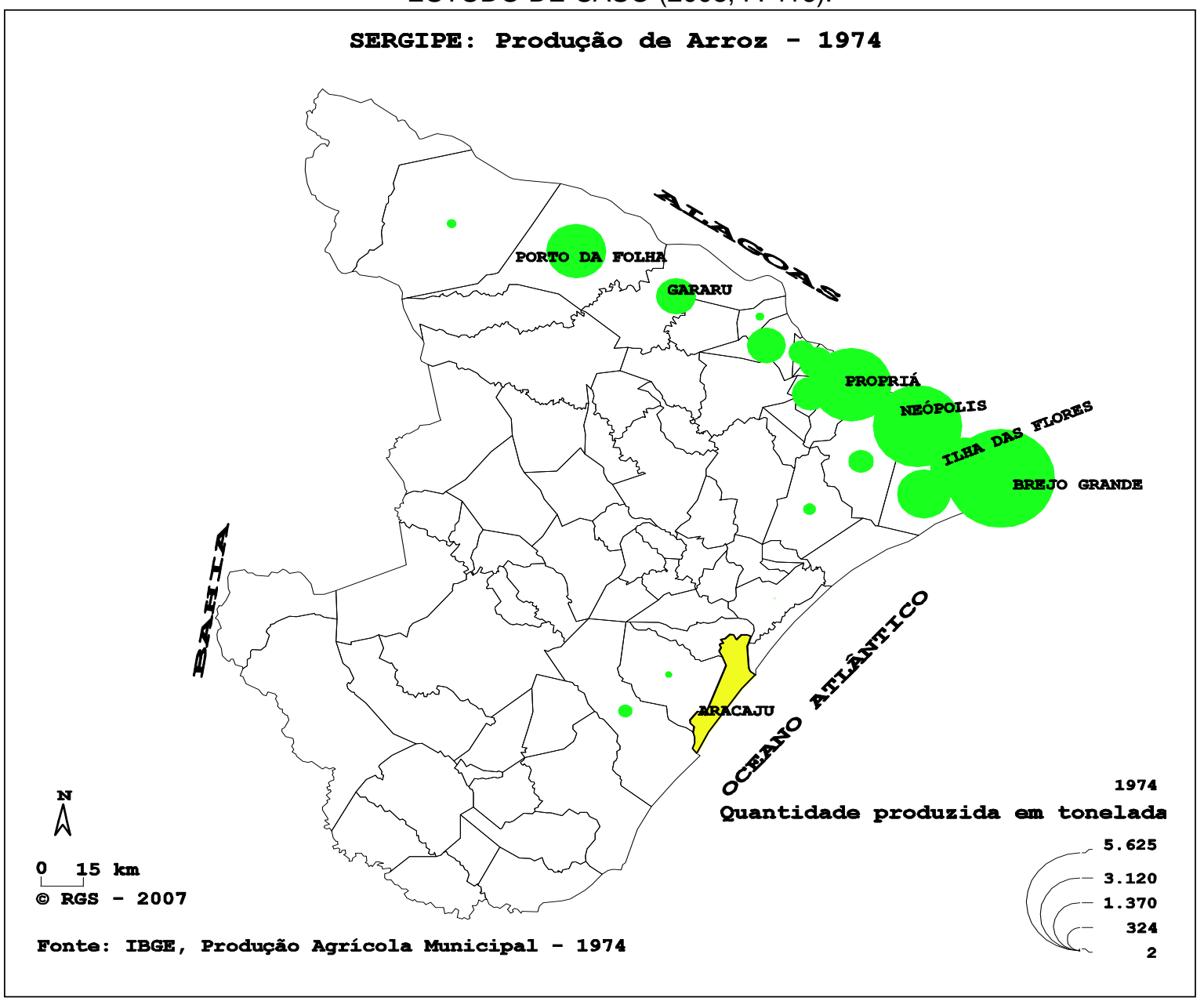


A viabilidade entre esse modelo de desenvolvimento e a preservação ambiental ratifica-se tanto com a pesquisa empírica realizada na área de estudo quanto conforme observa Ignacy Sachs (1998, p. 162):

[...] que pudesse nos conduzir a um desenvolvimento orientado pelo principio de justiça social em harmonia com a natureza, e não através de sua conquista. O crescimento seria sem dúvida necessário como substrato deste processo, mas deveria assumir um perfil diferente daquele que caracteriza o crescimento selvagem; acima de tudo, seus frutos deveriam ser utilizados e repartidos de outra maneira. Com outro nome - o ecodesenvolvimento [...], desenvolvimento durável ou viável [...] harmonização de objetivos sociais, ambientais e econômicos [...].

Além disso, é necessário preservar o meio ambiente para que ocorra a viabilidade entre esse e o desenvolvimento econômico através de planejamento eficaz, haja vista ao que observou Rosas, et.al. (1990, apud Vargas, 1999, p. 74 75):

Esta diferença do volume d'agua entre a cheia e a vazante possibilitou a formação de depressões em suas margens que se transformavam, anualmente, em lagoas que nas enchentes, permitiam a deposição de sedimentos e a adubação natural. As grandes oscilações de nível e volume d'agua e, consequentemente de área ocupada e de profundidade proporcionavam um permanente processo de interação entre os ambientes aquático e terrestre, com visíveis vantagens para ambos ecossistemas.

Assim, essa é mais uma vantagem do modelo de produção de arroz por via de ciclo natural de enchentes, entre tantas outras. Observa-se que é, pois, preciso preservar o ecossistema para que o homem possa continuar interagindo com o meio ambiente, porque antes de ser social ele pertence a esse mesmo meio e este faz parte da natureza.

\section{Uma análise sobre o mal uso de irrigação em cultura de arroz}

A irrigação mecanizada sendo mal utilizada sobre esse tipo de cultura pode ser a causa de um caos para o modelo de desenvolvimento em epígrafe, pois conforme Ross (2005, p. 226): 
O cultivo mecanizado é obrigatoriamente acompanhado do uso de fertilizantes químicos, e para controle das chamadas "ervas daninhas", ou do "mato", que nascem e crescem mais rapidamente que as espécies plantadas, aplicam-se os herbicidas, tão tóxicos quanto os venenos aplicados para controlar os insetos e fungos.

Levando-se em conta o sistema de irrigação agroindustrial, não precisa ir longe para perceber os conflitos que podem ser causados, tanto que várzeas sempre se encontram às margens de seus rios, no município portofolhense isso não é diferente.

Conflitos estes que giram em torno de toda uma discussão política, desde a forma de como acontece a irrigação pendendo para o desenvolvimento atrelado ao sistema do capitalismo selvagem, produção sobre produção, até a conciliação que deve ocorrer entre desenvolvimento econômico e preservação ambiental, conforme as necessidades atuais apontadas por ambientalistas.

Na política do sistema de irrigação, é possível notar o intenso uso de insumos agrícolas para o desenvolvimento de qualquer tipo de cultura que adote esse modelo, bem como a preconização do uso de fertilizantes e de até máquinas com tecnologia avançada para beneficiamento das lavouras. Com o manejo do solo de forma inadequada ou, pelo menos, com o cansaço desse que uma hora ou outra ocorrerá devido ao seu método de cultivo, aparecerão consequências graves, assim como sua infertilidade, no caso de grandes extensões de monoculturas.

Os atores desse modelo de desenvolvimento mecanizado que está diretamente ligado ao sistema capitalista, ultimamente, vêm sendo chamados para discussão com o objetivo de se encontrar uma forma mais viável para o atual desenvolvimento, cujo modelo causa tantos danos ao meio ambiente. Seus defensores atêm-se ao acúmulo de capitais e riquezas materiais, sendo também responsáveis pela criação das barragens no vale do São Francisco para atender, proporcionalmente, a seus interesses.

Contra esses precursores das desigualdades sociais e responsáveis pelos impactos ambientais e até sociais, consequentemente, encontram-se os defensores do meio ambiente que buscam uma forma de desenvolvimento da economia sem prejudicar o meio natural. Politicamente, os ambientalistas, em hipótese alguma 
aceitam a eliminação de um espaço onde uma cultura sempre se desenvolveu de forma natural, sem apresentar impactos negativos ao meio. De tal forma, a ocupação artificial desse espaço torna-se inviável ante tantas fontes de energia renovável que não degradam o meio ambiente tanto quanto a hidráulica em determinadas situações, por exemplo, no caso do modelo em epígrafe.

Ao contrário da irrigação mecanizada, o modelo de desenvolvimento da cultura arrozeira por via de ciclo natural de enchentes sempre trouxe resultados positivos e benéficos para os meios social e natural, em oposição ao modelo mecanizado (irrigação agroindustrial), que segundo Ross (2005, p. 226):

\begin{abstract}
A aplicação freqüente de quantidades cada vez maiores desses produtos químicos, genericamente chamados de insumos agrícolas, contamina o solo. Além disso, eles são transportados pela chuva para os riachos e rios, afetando, desse modo, a qualidade das águas que alimentam o gado, abastecem as cidades e abrigam os peixes. $O$ veneno afeta a fauna, e os pássaros e os peixes desaparecem rapidamente das áreas de monocultura, favorecendo a proliferação de pragas, lagartas, mosquitos e insetos em geral. A impregnação do solo com venenos e adubos químicos tende a torná-lo estéril pela eliminação da vida microbiana. [...].
\end{abstract}

Por isso, sempre há uma busca incessante de conciliar a preservação da natureza ao desenvolvimento econômico para que também, nessa imbricação, venha acontecer a justiça social.

Para que ocorra essa conciliação é necessário o diálogo e a compreensão entre os atores, além disso, que haja justiça.

Se há, pois, uma forma de se desenvolver sem prejudicar o meio ambiente, o bem de todos, degradar a natureza para acontecer o desenvolvimento da economia não é um caminho que o homem deve perfazer. Nessa concepção, se o homem vive o presente, por que economizar, aumentar suas riquezas infinitamente? Se ele vive o futuro, por que não preservar o meio ambiente, visto que necessitará deste profícuo à vida natural? Em razão disso, observa-se que se a natureza não existisse o homem também não existiria, já que ele é obra dessa mesma. 


\section{Uma análise sobre o modelo em epígrafe e uma breve avaliação sobre a várzea como "Área de Preservação Permanente"}

Aspectos naturais como exuberante vegetação e hidrografia com destaque para o denso lençol freático foram observados no lugar até enquanto durou o ciclo de cheias naturais do Velho Chico (rio São Francisco). Por causa dessas cheias, a área de planícies inundáveis de Porto da Folha/SE foi observada como um exemplo de paradigma de desenvolvimento sustentável através do importante desempenho natural da cultura do arroz. Foi na várzea Ilha do Ouro, a principal do município, que, no ciclo do arroz, se observou a relação homem natureza sem evidenciar degradação ambiental, pois a atividade do lavrador se concentrou em sua própria força.

Cabe levar em consideração, neste caso, o aproveitamento do aspecto natural tanto em termos de cultura quanto em viabilidade de preservação ambiental e desenvolvimento socioeconômico do lugar.

Devido à extinção do ciclo de cheias naturais no BSFS, hoje em dia não se colhe sequer um grão do cereal em Porto da Folha/SE, enquanto que nos anos de 1967/1969 se destacou com a terceira produção do Estado numa área cultivada de 960 ha, segundo Vargas (1999).

Consequentemente, a população de classe baixa que vivia da meação da cultura arrozeira e que dependia daquelas lavouras para sua subsistência ficou impossibilitada de cultivar o arroz, considerado como um bem necessário à sua vida. Em razão disso, a desigualdade social local ficou ainda mais acentuada porque a produção do arroz que era consumida durante todo o ano sobrava e era negociada na aquisição de outros bens de subsistência, assim como ocorria a troca de sacos de arroz por sacos de feijão, farinha de macaxeira, etc.

Mediante o paradigma agrícola contextualizado é possível observar que se torna inviável a irrigação de uma cultura de arroz às margens de rios, em razão da imposição do poder tecnológico agrícola (agricultura capitalizada), quando se parte para o uso de insumos e, em especial, o uso de fertilizantes químicos. 


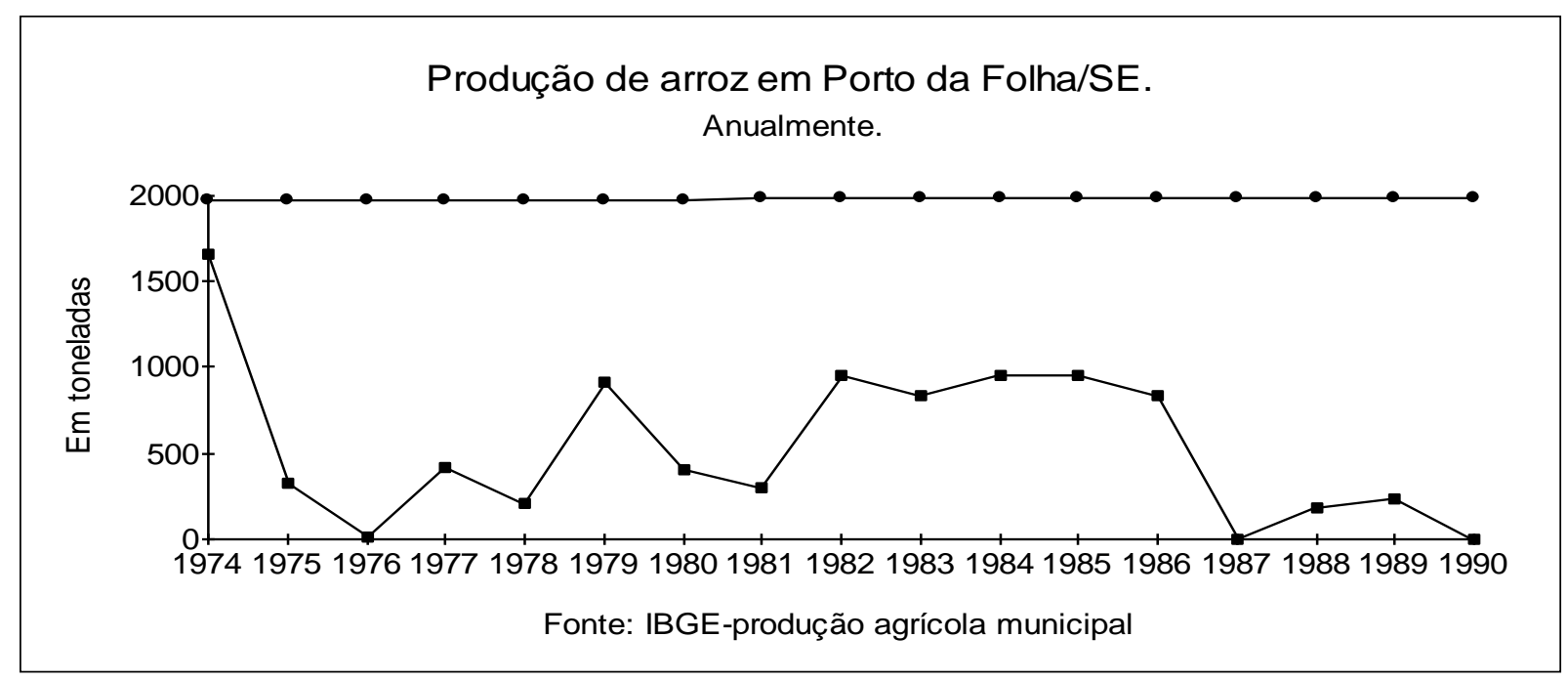

De acordo com o gráfico é possível perceber a importante produção que perdurou no lugar durante o ciclo do arroz. Nota-se também, principalmente, que a queda da produção arrozeira se dá a partir do instante em que as obras da barragem Xingó se realizam, 1987.

Com o término das obras da barragem, em 1994, nesse ano ainda foi registrada colheita numa área de 150 ha e em 1997, 30 ha. Essas áreas só foram colhidas por motivo de as comportas da barragem permanecerem abertas em tempo determinado devido ao grande volume de água que recebeu, afluxo, não podendo esperar, pois, o transbordamento. Assim, confirmou-se a extinção da cultura do arroz na várzea do município de Porto da Folha/SE, pois a partir daqueles anos não teve mais colheita do cereal, conforme dados do IBGE. Com isso, o modelo que perdurou por mais de século e de grande relevância para o mundo contemporâneo que se aflige quanto à questão ambiental foi extinto do lugar.

Nesse ponto de vista, cabe frisar que, quanto mais a utilidade das barragens hidroelétricas tende a diminuir à medida que a sedimentação atinge os reservatórios a ponto de inviabilizar a geração de energia, menos se torna viável esse modelo energético. Em razão disso, segundo Marks (2007, p. 79): 
A desativação de represas (particularmente as pequenas, como é o caso da de Fossil Creek) está se tornando um acontecimento rotineiro. Usinas antigas fornecem uma parcela cada vez menor da energia consumida em cada região ou se tornam perigosas ou caras demais para serem restauradas.

Daí por que as Usinas Hidroelétricas nessa situação se tornam obsoletas na ótica do sistema capitalista. Consequentemente, os empreendedores desse segmento procuram novas áreas, para instalação de novas barragens, que poderão sofrer os mesmos impactos pelos quais o espaço das velhas barragens foi atingido.

Nessa concepção, observa-se que é tempo de corrigir erros causados pela ação antrópica por haver tantas novas fontes energéticas corretamente viáveis. Assim, é inaceitável ver tamanhos impactos negativos, causados devido à existência de barragens, não serem corrigidos.

De acordo com o Código Florestal Brasileiro (2005), a várzea do município de Porto da Folha/SE, pode ser considerada uma Área de Preservação Permanente (APP). Apesar disso, atualmente está praticamente ausente da caracterização legal, porque a maioria de sua área se encontra à margem do riacho Capivara, um rio intermitente de leito muito estreito em relação à área da várzea. Isso ocorre em consequência da ausência das cheias que naturalmente não existem mais em ciclo devido ao represamento de grande volume de água na barragem Xingó. Quem observasse a várzea no ciclo de cheias naturais notava o rio São Francisco submergindo o rio Capivara, dando a impressão de que ali era um só rio.

Segundo o Conselho Nacional do Meio Ambiente (CONAMA) (2005), é possível, excepcionalmente, a intervenção em APPs. Desde que seja para a implantação de projetos de interesse social e para a realização de ações consideradas eventuais e de baixo impacto, sendo aqui subentendido o mínimo de impacto possível, ou a ausência deste. Observa-se que essa intervenção deve ser sempre de forma sustentável e de acordo com todas resoluções do CONAMA que tratam dessa questão.

No entanto, o modelo em epígrafe, em momento algum exigiu ou admitiu a degradação ambiental. Em contrapartida, sempre colaborou com a ação da natureza, de forma que o cultivo foi consequência dessa ação. Ou seja, se não acontecesse a ação da natureza, as enchentes sobre a várzea e todas as vazantes 
margeantes do rio Capivara, afluente do São Francisco, não ocorreria produção das lavouras e tampouco estas existiriam.

Enfim, é necessário levar em consideração o estado em que se encontra a várzea hoje, parecendo um ermo, e como sempre se caracterizava, para entender que o modelo de cultivar arroz via ciclo natural de enchentes, de forma devidamente respeitável ao meio ambiente, não é inviável nem ilegal. Além disso, conforme já foi afirmado, os lavradores desta cultura tinham uma inter-relação presente entre o modelo de cultivar e as ações do meio ambiente.

\section{RESULTADOS E DISCUSSÕES}

A presente pesquisa revelou que este modelo de desenvolvimento de cultura é um dos meios mais viáveis em se tratando de relação sociedade natureza. Isso foi observado em relação ao desenvolvimento socioeconômico e ambiental que existiu no lugar enquanto o ciclo do arroz perdurou. Isto é, desde a plantação até a colheita, nunca foi notado e tampouco aplicado insumos ou qualquer agrotóxico, por necessidade. Sempre ocorreu uma produção equânime que abasteceu a comunidade local, apesar da colheita em alguns momentos se destacar com grande volume pelo fato de ter sido maior o contingente envolvido na mão-de-obra em momentos de melhores condições naturais. Por esta razão, explica-se a exportação do excedente da produção para outras regiões internas do país, o que é mais viável do que estruir o que foi conseguido com tanto sacrifício.

É importante ressaltar que esse excedente de produção se dava por benefício da natureza, mas não por emprego de agrotóxico ou técnicas avançadas que vemos hoje em todo o mundo. Observou-se que o desenvolvimento de cultura arrozeira através de sistema de irrigação mecanizado inadequado, às margens de rio, pode acarretar significativos impactos ao meio ambiente.

Em termos de sazonalidade, o modelo de desenvolvimento da cultura de arroz ocorrido em Porto da Folha/SE foi o único e exclusivamente que se adequou ao clima daquele município e seus aspectos naturais até enquanto ali não sofria políticas regionais inadequadas. Referentemente a isso, o cultivo começava no outono e findava na primavera. 
O arroz foi introduzido como atividade cultural no Brasil pelos portugueses em fins do século XVII através de uma espécie conhecida como Orysa Sativa, importada da Índia. Segundo Sergipe (1972), a primeira plantação do cereal ocorreu às margens do rio Poxim, em 1614.

Partindo dessa concepção, pode-se dizer que o Estado de Sergipe foi privilegiado quanto à cultura arrozeira no tocante ao despontar da existência desse tipo de lavoura no Brasil. Observou-se que, com a existência do cereal em território nacional, a forma de cultivo em epígrafe se apresentou favorável àquele lugar. Referentemente a isso, a presente pesquisa revelou que tal modelo não causa impasses ao aspecto natural quanto ao referido lugar por ser mais adequado para seu desenvolvimento, em contrapartida aos modelos mecanizados e artificiais hoje existentes em diversas partes do mundo por meio de irrigações.

Assim, como o arroz aparece pela primeira vez no Brasil às margens do rio Poxim, percebeu-se que o cereal se adequou primordialmente, em termos de desenvolvimento, na várzea desse rio. Igualmente aconteceu, depois desse episódio, com o processo de desenvolvimento da cultura arrozeira nas várzeas do Baixo São Francisco Sergipano (BSFS). Isso foi notável no período que se antecedeu à existência dos controles de vazão através das barragens existentes ao longo do curso do rio São Francisco, se destacando aqui a várzea de Porto da Folha/SE. Conforme foi contextualizado, esta várzea só veio sofrer interrupção em sua cultura arrozeira, depois da existência da barragem Xingó (final do século XX). 
FIGURA 02. MAPA REPRESENTANDO A EXTINÇÃO DE CULTURA DE ARROZ EM PORTO DA FOLHA/SE.

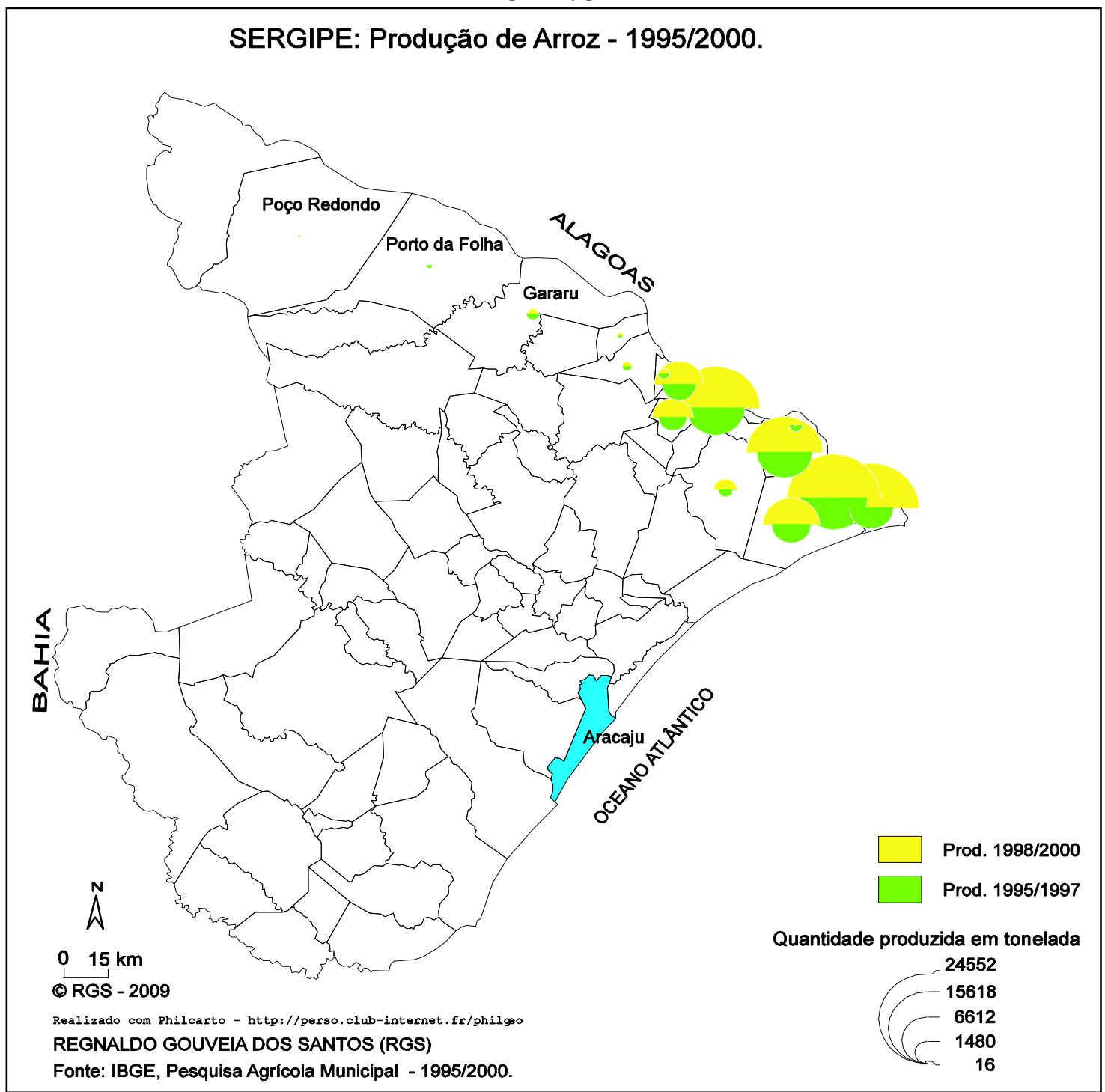

Da análise do mapa é possível observar o fim da produção arrozeira no município portofolhense a partir de 1998, o que contextualiza a extinção da cultura do cereal, pois dessa data até os dias atuais não há registro do produto. Percebe-se também que isso se deu na década de 1990 quando a barragem já estava em atividade.

As vantagens que foram observadas em relação ao modelo em epígrafe são muitas. Merecem destaque, entre outras, a não utilização de insumos e agrotóxicos no cultivo e a autofertilização do solo. Isso se resume à preservação da natureza, tema muito discutido, ultimamente, devido ao aquecimento global. É pertinente entrar nesse assunto, pois para obter os bons resultados no cultivo do arroz a 
comunidade ribeirinha do BSFS, como a portofolhense, nem desmatava as várzeas, nem praticava queimadas nas mesmas, de forma devastadora. Tampouco a natureza agia ao contrário, visto que essa foi o principal fator que contribuiu com tais vantagens conforme foi contextualizado.

Observou-se que a principal várzea de Porto da Folha/SE é uma APP de acordo com o Código Florestal Brasileiro, embora esteja, atualmente, descaracterizada como Área de Preservação Permanente devido à significativa diminuição da vazão do rio São Francisco. Quanto à diminuição da vazão do rio, esse já atingiu os $13.000 \mathrm{~m}^{3} / \mathrm{s}$, mas, atualmente, segundo Santos (2008) não tem atingido com frequência os $3.000 \mathrm{~m}^{3} / \mathrm{s}$, o que acarretou a extinção do ciclo de cheias naturais.

Foi possível observar também que, de maneira excepcional, as APPs podem sofrer intervenções para atender a projetos sociais, desde que sejam consideradas de baixo impacto.

\section{CONCLUSÃO}

O presente estudo evidenciou que é possível cultivar arroz por via de ciclo natural de enchentes sem degradar o meio ambiente. Dessa forma, o modelo como os ribeirinhos do lugar, Porto da Folha/SE, cultivava o cereal, de maneira que se valiam dos aspectos naturais, locais e regionais, merece importante destaque perante a crise ambiental que o mundo contemporâneo vem enfrentando. Com isso, cabe frisar que o referido modelo é viável ao meio ambiente, pois sua execução não tem causado implicações negativas nem à natureza de forma significativa, nem à sociedade.

O fenômeno natural que ocorria através do rio São Francisco era o principal fator de onde partiam todas as vantagens em relação ao desenvolvimento do modelo cultural praticado pelos ribeirinhos. Entre tantas vantagens, é importante salientar que por causa da natureza local e regional o ribeirinho do BSFS não precisava utilizar agrotóxicos ou insumos agrícolas para cultivar o arroz, o que é relevante para a preservação ambiental. 
$\mathrm{Na}$ certeza da existência do modelo cultural em epígrafe o uso de irrigação no cultivo de arroz em vazante torna-se inviável ao meio ambiente devido à imperativa necessidade do uso de agrotóxicos ou insumos agrícolas. Assim, ao comparar os dois modelos prevalece a incerteza sobre o sistema de irrigação quando mal executado em espaços que requerem atenção especial em relação ao meio ambiente. Ainda que se execute um sistema de irrigação em rizicultura e em área de vazante é preciso, a princípio, estudo criterioso e particular atenção quanto à circunstância ambiental local. Isso não descarta a viabilidade ou inviabilidade ambiental, tudo dependerá do estudo e da seriedade dos avaliadores de tal questão.

É possível afirmar que o modelo de se cultivar arroz por via de ciclo natural de enchentes contribuía com certo equilíbrio sobre a diferença entre classes sociais, pelo menos, de média à miserável, pois os ribeirinhos mais pobres tinham alimentação em fartura.

Se, por um lado, afirmar que a várzea principal de Porto da Folha/SE não é uma APP estaria colocando a questão diante de um dilema, por outro, a ciência clarifica que aquela área perante a natureza não pode deixar de ser APP. Em razão disso, ainda que demore a retomada da caracterização natural da várzea, será possível que seu ecossistema seja revigorado, apesar de depender do bom senso das autoridades competentes em suas tomadas de decisões.

Assim, cabe frisar que o homem poderia ser mais consciente e plausível nas decisões que envolvem desenvolvimento econômico e meio ambiente. Igualmente, que, em decisões desse tipo, não aja sobre um espaço e tempo desconhecidos, pois para os ambientalistas, quando a ação humana vem de encontro a essas considerações, o próprio homem ratifica muitos erros, assim como causando impactos socioambientais.

Observou-se que o desenvolvimento do modelo em epígrafe foi interrompido devido à falta de um estudo eficaz sobre a previsão de impactos. Nessa concepção, se esse estudo levasse em consideração o espaço total, o qual abrange tanto a instalação do empreendimento hidroelétrico em questão quanto a relação da comunidade ribeirinha com a natureza, o ciclo do arroz em Porto da Folha/SE poderia continuar existindo até hoje.

A preconização desta proposta de paradigma, como se desenvolve economia 
preservando o meio ambiente, ressalta que nem sempre a ação tecnológica do homem é necessária sobre o espaço para se obter bons resultados. Referentemente a isso, na maioria das vezes os bons frutos acontecem naturalmente, assim como uma arvore frutífera em seu tempo de colheita sacia a necessidade do homem faminto à beira de seu desfalecimento. Em contrapartida, diante do sistema de economia contemporâneo, um homem plenamente digno, sem oportunidades afins, corre o risco de morrer de forme, dependendo do espaço geográfico onde ele estiver.

Enfim, aqui também foi enfatizado que sejam tomados os rumos das orientações legais e as recomendações científicas adequadas a cada situação, neste caso, o desenvolvimento sustentável, ou, pelo menos, o mais viável em termos de previsão de impacto sobre o meio ambiente. Em razão disso, evidenciouse que cultivar arroz por via de ciclo natural de enchentes pode ser uma das vias que o homem pode perfazer para alcançar o tão almejado desenvolvimento sustentável. Para o alcance desse desenvolvimento, é preciso implementar políticas socioeconômicas, de forma efetiva e eficaz. Além disso, que todas venham ao encontro da preservação da natureza.

Desenvolvimento tecnológico sempre será importante e bem vindo ao homem, desde que ele não se induza, tampouco vá, com suas ações, causar ou venha aceitar a sua substituição ao artificial. O homem não deve, pois, agir impactando irreversivelmente o meio natural em que vive e do qual necessita para viver. 


\section{REFERÊNCIAS}

BRASIL. Código (1965). Código Florestal Brasileiro: Lei 4.771. Brasília: Congresso Nacional, 1965. p. 01-14.

BRASIL. Processo no 02000.002382/2003-92, de 02 e 05 de maio de 2005. Dispõe sobre Proposta de Resolução sobre APP. CONAMA, Brasília, DF, 02 e 05 de maio de 2005. Versão 4 LIMPA.

CUNHA, José Carlos Santos. Técnicas agrícolas tradicionais: - eficiência social/ambiental no Semi-Árido sergipano. 1997. 154 f. Dissertação de Mestrado NPGEO/UFS, Aracaju, 1997.

INSTITUTO BRASILEIRO DE GEOGRAFIA E ESTATÍSTICA. Produção agrícola: discriminada por município - 1953 - Sergipe. Rio de Janeiro: IBGE, 1954.

Produção agrícola: discriminada por município - 1974-2000 - Sergipe. Rio de Janeiro: IBGE, (27 vols.).

MARKS, Jane C. Abaixo as represas. Scientific American Brasil, São Paulo, ed. 59, p. 78-83, abril 2007.

MELLO, Neli Aparecida de. Aula ministrada por Neli Mello, Faculdade de Filosofia, Letras e Ciências Humanas, da Universidade de São Paulo, em 25 de abril de 2006.

ROSS, Jurandir L. Sanches (org.). Geografia do Brasil. - 5a edição. rev. e ampl. São Paulo: Edusp, 2005. p. 225-231.

SACHS, Ignacy. Do Crescimento Econômico ao Ecodesenvolvimento. In: VIEIRA, Paulo Freire. et al. (org.). Desenvolvimento e Meio Ambiente no Brasil: a Contribuição de Ignacy Sachs. Porto Alegre: Pallotti; Florianópolis: Aped, 1998. p. 161-163. $448 \mathrm{pg}$.

SANTOS, Regnaldo Gouveia dos. Impactos socioambientais à margem do rio São Francisco: um estudo de caso. 2008. 193 f. Dissertação de Mestrado DPGEO/FFLCH-USP, São Paulo, 2008.

SERGIPE. SUVALE/ANCARSE. Plano de ação para os vales úmidos do Baixo São Francisco em Sergipe. Aracaju: ANCARSE, 1972.

VARGAS, Maria Augusta Mundim. Desenvolvimento Regional em Questão: Baixo São Francisco Revisitado. São Cristóvão: NPGEO/UFS, 1999. p. 74-115.

VIEIRA, Paulo Freire \& WEBER, Jacques (orgs.). Gestão de Recursos Naturais Renováveis: Novos Desafios para a Pesquisa Ambiental. 3ª ed. São Paulo: Cortez, 2002. p. 17

(Recebido em abril/2009. Aceito em agosto/2009) 